\title{
Peripheral Arterial Disease among Diabetic Patients in Dr. Hasan Sadikin General Hospital Bandung 2012
}

\author{
Feriska Fairuz Azkiyah,, ${ }^{1}$ Teguh Marfen Djajakusumah, ${ }^{2}$ RA. Retno Ekowati ${ }^{3}$ \\ ${ }^{1}$ Faculty of Medicine Universitas Padjadjaran, ${ }^{2}$ Department of Surgery Faculty of Medicine \\ Universitas Padjadjaran/Dr. Hasan Sadikin General Hospital, ${ }^{3}$ Departement of Biochemistry and \\ Molecular Biology Faculty of Medicine Universitas Padjadjaran
}

\begin{abstract}
Background: As one of the most devastating complication in diabetes mellitus, peripheral arterial disease is still under detected in health care services. This study aimed to reveal the frequency of peripheral arterial disease in diabetic patients in Endocrine and Metabolism Clinic in Dr. Hasan Sadikin General Hospital Bandung.

Methods: A cross sectional descriptive study was conducted during the period of October to November 2012 in Endocrine and Metabolism Clinic in Dr. Hasan Sadikin General Hospital Bandung. As many as 54 patients who met the inclusion criteria and agreed to participate in this study signed the informed consent form then underwent history taking, simple physical examination of lower extremities, and Ankle-Brachial Index (ABI) measurement. Normality of the data distribution was calculated by Kolmogorov-Smirnov test. Results: From a total 54 diabetic patients enrolled, it was found 18 cases of peripheral arterial disease, consisted of 10 patients with Ankle-Brachial Index measurement $\leq 0.9$ and 8 patients with Ankle-Brachial Index measurement $>1.4$. Most of the cases occurred in the elderly group ( $>60$ years old) and had been diagnosed diabetes less than 10 years.

Conclusions: The frequency of peripheral arterial disease in diabetic patients attended Dr. Hasan Sadikin General Hospital Bandung is 33.3\% and more prevalent in elderly patients. It occurred mostly in patients diagnosed with diabetes less than 10 years. [AMJ.2015;2(1):287-90]
\end{abstract}

Keywords: Diabetes mellitus, frequency, peripheral arterial disease

\section{Introduction}

Peripheral Arterial Disease (PAD) is a vascular derangement where there is an obstruction or constriction in the aorta or artery of the extremities. ${ }^{1,2}$ It is mostly caused by atherosclerosis. ${ }^{1,3}$ One of the condition that promotes atherosclerosis is diabetes mellitus. ${ }^{4}$ Moreover, diabetic patients who have PAD tend to have more amputations, five times greater than normal population. ${ }^{5}$

In general population, Multi Ethnic Study of Atherosclerosis (MESA) study showed that the prevalence of PAD is $3.7 \% .^{6}$ Prevalence of PAD in diabetic patients is higher, range from $3.2 \%$ in Korea $^{7}$ to $15.2 \%$ in Singapore. ${ }^{8}$ In the United States ${ }^{9}$, the prevalence of PAD in diabetic patients is two times higher compared with normal population. Regardless the high prevalence, PAD is undetected in healthcare services.

Indonesia ranks as the forth country with most people with diabetes mellitus after India, China and the United States. In 2030 prediction, Indonesia will occupy the same rank. ${ }^{10}$ Based on Indonesian Basic Health Research (Riset Kesehatan Dasar/Riskesdas) ${ }^{11}$ in 2007, prevalence of diabetes mellitus in Indonesia was as high as $5.7 \%$. According to a research conducted in Primary Health Care Services in Medan $^{12}$, prevalence of PAD in diabetic patients is $44 \%$. There is insufficient data about prevalence of PAD in diabetic patients in other geographic setting in Indonesia. This study was conducted to find the prevalence of PAD in diabetic patients who visited the Endocrine and Metabolism Clinic in Dr. Hasan Sadikin General Hospital Bandung during the period of October-November 2012.

\section{Methods}

This is a cross-sectional descriptive study which had been approved by Health Research

Correspondence: Feriska Fairuz Azkiyah, Faculty of Medicine, Universitas Padjadjaran, Jalan Raya Bandung-Sumedang Km.21, Jatinangor, Sumedang, Indonesia, Phone: +628122010004 Email: feriskafairuz@yahoo.com 
Table 1 Results of ABI Measurement in Diabetic Patients

\begin{tabular}{lcc}
\hline \multicolumn{1}{c}{ ABI Result } & Frequency & Percentage \\
\hline PAD Definitive & 9 & 16.7 \\
Normal & 29 & 53.7 \\
Uncompressible & 15 & 27.8 \\
$\mathrm{ABI}<1.4$ & 7 & 13.0 \\
$\mathrm{ABI} \geq 1.4$ & 8 & 14.8 \\
PAD Definitive and Uncompressible & 1 & 1.9 \\
\hline
\end{tabular}

Ethics Committee, Faculty of Medicine, Universitas Padjadjaran. The subjects in this study were diabetic patients who visited Endocrine and Metabolism Clinic in Dr. Hasan Sadikin Hospital General Bandung. The study was conducted from October to November 2012. Patients with history of lower extremity amputation who had serious morbidity or in diabetic foot treatment were excluded from the study. Patients who met the inclusion criteria and agreed to participate in this study signed the informed consent form then underwent history taking, simple physical examination of lower extremities, and Ankle-Brachial Index (ABI) measurement. As many as 54 patients underwent the study procedure.

Anamnesis consisted of patient's identity and some of risk factor history. Patient's characteristics such as age and length of diabetes duration were documented for later grouping in intervals. Physical examination consisted of inspection of lower extremity and palpation of lower extremity arterial pulses in dorsal for pedis artery and posterior tibial artery. Measurement of ABI had been done in both lower extremity with a calibrated mercury spigmomanometer and a handheld DOPPLER ultrasound. The lower extremity pressures was compared with the brachial pressure and resulted the ABI score. The score then grouped to PAD definitive (ABI $\leq 0.9$ ), normal (ABI0.911.30) and uncompressible (ABI>1.3). For the importance of PAD status determination, the uncompressible group divided into two more groups, uncompressible $\leq 1.4$ and uncompressible $>1.4$. PAD defined as having $\mathrm{ABI}$ score less than or equal to 0.9 or more than 1.4. Patients with ABI score $>1.4$ were included in PAD criteria based on a research which stated that a high ABI score $(>1.4)$ could be considered as PAD-equivalent. All data processed by Microsoft Excel 2007 and SPSS version 17.0. Normality of the data distribution was calculated by Kolmogorov-Smirnov test.

\section{Results}

Total 54 diabetic patients enrolled in this study, consisted of 22 males and 32 females ranging from 36 years old to 81 years old with normal distribution. All patients followed ABI measurement. The majority of the patients had normal ABI score, 9 people had PAD definitive, 15 people had uncompressible, and 1 person had both PAD definitive and uncompressible result. In uncompressible group, 7 had $A B I$ score $<1.4$ and 8 had ABI score $\geq 1.4$ (Table 1 )

The frequency of PAD among diabetic patients was $33.3 \%$ (18 people), 10 people with PAD definitive and 8 people with ABI score $\geq 1.4$ (Table 2). Half of the diabetic patients who had PAD were in the elderly group (Table 3). Most of the patients who had PAD were diagnosed as having diabetes $\leq 10$ years (Table 4).

\section{Discussions}

Measurement of $\mathrm{ABI}$ is the most simple, non-

Table 2 Frequency of PAD among Diabetic Patients

\begin{tabular}{lcc}
\multicolumn{1}{c}{ Criteria } & Frequency & Percentage \\
\hline PAD & 18 & 33.3 \\
PAD definitive & 10 & 18.5 \\
Uncompressible, ABI $\geq 1.4$ & 8 & 14.8 \\
Non-PAD & 36 & 66.7 \\
\hline
\end{tabular}


Feriska Fairuz Azkiyah, Teguh Marfen Djajakusumah, RA. Retno Ekowati: Peripheral Arterial Disease among 289 Diabetic Patients in Dr.Hasan Sadikin General Hospital 2012

Table 3 Age Characteristic of Diabetic Patients with PAD

\begin{tabular}{|c|c|c|c|c|c|c|c|c|c|c|}
\hline \multirow{3}{*}{ PAD group } & \multicolumn{8}{|c|}{ Age groups (years old) } & \multirow{2}{*}{\multicolumn{2}{|c|}{ Total }} \\
\hline & \multicolumn{2}{|c|}{$<40$} & \multicolumn{2}{|c|}{ 40-49 } & \multicolumn{2}{|c|}{$50-59$} & \multicolumn{2}{|c|}{$\geq 60$} & & \\
\hline & $\mathrm{f}$ & $\%$ & $\mathrm{f}$ & $\%$ & $\mathrm{f}$ & $\%$ & $\mathrm{f}$ & $\%$ & $\mathrm{f}$ & $\%$ \\
\hline PAD definitive & 1 & 6 & 0 & 0 & 4 & 22 & 5 & 28 & 10 & 56 \\
\hline $\mathrm{ABI}>1.4$ & 1 & 6 & 0 & 0 & 3 & 17 & 4 & 22 & 8 & 44 \\
\hline Total & 2 & 11 & 0 & 0 & 7 & 39 & 9 & 50 & 18 & 100 \\
\hline
\end{tabular}

invasive method to document PAD in lower extremities. A lower than normal ABI score showed an occurence of abnormal vascular hemodynamic, thus diagnosed as PAD. ${ }^{13}$ However, diabetic patients had a unique characteristic where they tend to have a higher ABI score than expected. It occurred because of the calcification in the arterial wall causing the wall to be stiffened. ${ }^{4,13}$ A Strong Heart Study revealed that a high $\mathrm{ABI}$ score had a same mortality risk as a low ABI score, so patients with high ABI score should not be neglected. ${ }^{14}$ For diabetic patients, a high ABI score could be categorized as PAD-equivalent. ${ }^{15}$ It is the reason why in this study included the high $\mathrm{ABI}$ score patients to the PAD group along with patients with low ABI score. This made our study is different with other study.

This study showed that $33.3 \%$ percent of diabetic patients had PAD, either PAD definitive or high ABI score. Compared to another study conducted in Indonesia ${ }^{12}$, this study showed a lower frequency. It should be due to demographical differences between our study places. A study conducted in Sweden ${ }^{16}$ showed that PAD prevalence can be varied within different geographical places, influenced by clinical setting, ethnicity, and other risk factors related. The same reason goes to the differences between our study result and other results in Singapore, South Korea and United States. Unfortunately, this study did not cover and analyze a thorough data collection about risk factors. Therefore, another comprehensive study is needed.

Data about age of diabetic patients who had PAD showed a similar result with other previous study.$^{13}$ Frequency of PAD rises along with the advanced of age. This study showed that PAD occurred mostly in patients aged more than 60 years old.

This study concerned with the duration of diagnosis showed an interesting result. A theory stated that chronic complication of diabetes usually appears at the second decade of hyperglycemia ${ }^{5}$, but it showed that majority of diabetic patients with developed PAD were at the first ten years of diabetes. It should be due to that hyperglycemic condition had occurred long before the patient was diagnosed of having diabetes. ${ }^{5}$ Also it should consider the influence of other risk factors such as smoking history, coronary arterial disease, and hypertension. Despite this silent nature of PAD, PARTNERS study which was conducted in United States showed that doctor's attention to PAD detection is low. ${ }^{17}$ Although there is no explicit data about $\mathrm{ABI}$ measurement in Indonesia, it is done less likely because most of the study participants admitted never done a blood pressure measurement on lower extremities.

This study has limitations including the sampling technique, biases, and collected data for the study. The study sample has the minimum sample size needed but this study used a convenience sampling thus bias is more likely to happen. It is suggested that another

Table 4 Duration of Diagnosis Characteristic from Diabetic Patients with PAD

\begin{tabular}{|c|c|c|c|c|c|c|}
\hline \multirow{3}{*}{ PAD group } & \multicolumn{4}{|c|}{ Duration of diagnosis } & \multirow{2}{*}{\multicolumn{2}{|c|}{ Total }} \\
\hline & \multicolumn{2}{|c|}{$\leq 10$ years } & \multicolumn{2}{|c|}{$>10$ years } & & \\
\hline & f & $\%$ & f & $\%$ & f & $\%$ \\
\hline PAD definitive & 8 & 44 & 2 & 11 & 10 & 56 \\
\hline $\mathrm{ABI}>1.4$ & 6 & 33 & 2 & 11 & 8 & 44 \\
\hline Total & 14 & 78 & 4 & 22 & 18 & 100 \\
\hline
\end{tabular}


study with probability sampling method to be conducted with a larger scale in Indonesia. It is expected that another study will be conducted about diabetes, PAD, and all related risk factors related so the connections between all of it in Indonesia can be identified.

Although this study has many limitations, it showed a generally similar result with other study except for the findings about duration of diabetes which is sooner in this study. This study should also be used for a stepping stone to another study concerning PAD and diabetes and to help many diabetic patients to prevent developing PAD.

\section{References}

1. Fauci AS, Braunwald E, Kasper DL, Hauser SL, Longo DL, Jameson JL, et al., editors. Harrison's principles of internal medicine. 17th ed. New York: McGraw-Hill; 2008.

2. Dieter RS, Jr. RAD, III RAD, editors. Peripheral arterial disease. New York: McGraw-Hill; 2009.

3. Coffman JD, Eberhardt RT, editors. Peripheral arterial disease, diagnosis and treatment. New Jersey: Humana Press; 2003.

4. Cronenwett JL, Johnston KW, editors. Rutherford's vascular surgery. 7th ed. Philadelphia: Saunders 2010.

5. Jude EB, Oyibo SO, Chalmers N, Boulton AJM. Peripheral arterial disease in diabetic and nondiabetic patients. Diabetes Care. 2001;24(8):1433-7.

6. McDermott MM, Liu K, Criqui MH, Ruth K, Goff D, Saad MF, et al. Ankle-brachial index and subclinical cardiac and carotid disease, the multi-ethnic study of atherosclerosis. Am J Epidemiol. 2005;162(1):33-41.

7. Yu JH, Hwang JY, Shin M-S, Jung CH, Kim EH, Lee SA, et al. The prevalence of peripheral arterial disease in Korean patients with type 2 diabetes mellitus attending a University Hospital. Diabetes Metab J. 2011;35(6):543-50.

8. Narayanan RML, Koh WP, Phang J, Subramaniam T. Peripheral arterial disease in community-based patients with diabetes in Singapore: results from a primary healthcare study. Ann Acad Med
Singapore. 2010;39(7):525-31.

9. Gregg EW, Sorlie P, Paulose-Ram R, Gu Q, Eberhardt MS, Wolz M, et al. Prevalence of lower-extremity disease in the U.S. adult population $>40$ years of age with and without diabetes. Diabetes Care. 2004;27(7):1591-7.

10. Wild S, Roglic G, Green A, Sicree R, King H. Global prevalence of diabetes, estimates for the year 2000 and projections for 2030. Diabetes Care. 2004;27(5):1047-53.

11. The National Institute of Health Research and Development $\mathrm{MoH}$, Republic of Indonesia. Report on result of national basic health research (RISKESDAS) 2007. Jakarta: Ministry of Health, Republic of Indonesia, 2008.

12. Sihombing B. Prevalensi penyakit arteri perifer pada populasi penyakit diabetes melitus di Puskesmas Kota Medan [thesis]. Medan: University of Sumatera Utara; 2008.

13. Norgren L, Hiatt WR, Dormandy JA, Nehler MR, Harris KA, Fowkes FG, et al. Intersociety consensus for the management of peripheral arterial disease (TASC II). J Vasc Surg. 2007;45 Suppl S(1):S5-67.

14. Resnick HE, Lindsay RS, McDermott MM, Devereux RB, Jones KL, Fabsitz RR, et al. Relationship of high and low ankle brachial index to all-cause and cardiovascular disease mortality: the strong heart study. Circulation. 2004;109(6):733-9.

15. Aboyans V, Ho E, Denenberg JO, Ho LA, Natarajan L, Criqui MH. The association between elevated ankle systolic pressures and peripheral occlusive arterial disease in diabetic and nondiabetic subjects. J Vasc Surg. 2008;48(5):1197-203.

16. Sigvant $B$, Rolandsson $O$, Wiberg-Hedman $\mathrm{K}$, Andersson B, Bergqvist D, Persson E, et al. A population-based study of peripheral arterial disease prevalence with special focus on critical limb ischemia and sex differences. J Vasc Surg. 2007;45(6):118591.

17. Hirsch AT, Criqui MH, Treat-Jacobson D, Regensteiner JG, Creager MA, Olin JW, et al. Peripheral arterial disease detection, awareness, and treatment in primary care. JAMA. 2001;286(11):1317-24. 